\title{
REALISASIFRASA ATRIBUTIF DALAM WACANA NARASI MAHASISWA UNIVERSITAS BINA DARMA DAN APLIKASINYA DALAM PEMBELAJARAN
}

\author{
Andina Muchti \\ Dosen Universitas Bina Darma \\ Jalan Jenderal Ahmad Yani No. 3 Palembang
}

Sur-el: andina.muchti@binadarma.ac.id

Article info

Article history:

Received: 14-04-21

Revised : 28-04-21

Accepted: 30-05-21

Keywords:

Attributive Endocentric

Phrases,

Phrase Editing, and

Narrative Text

Kata Kunci:

Frasa Endosentris

Atributif,

Menyunting Frasa, dan

Wacana Narasi.

\begin{abstract}
A B S T R A C T
This research will describe attributive endocentric phrases in the narration text student of Bina Darma University, and the application of Bahasa Indonesia learning, especially material for editing phrases. The method used in this research is a qualitative description method. This data research is in the form of words and phrases. The data source for this research is the narrative story student of Bina Darma University. The data collection technique used was the reading and note taking technique. Data analysis using descriptions. The research results presented in this article as a sample are 5 data. The data is intended to be realized in Indonesian language learning, especially the material of editing phrases. The realization of the results of the analysis of attributive endocentric phrases in learning can be applied in the teaching material for editing phrases. The teacher can use the results of the analysis as teaching material in the learning process which is conveyed in the lesson plan.
\end{abstract}

Penelitian ini mendeskripsakan frase endosentris atributif dalam tulisan berbentuk narasi oleh mahasiswa Universitas Bina Darma, serta aplikasinya dalam pembelajaran Bahasa Indonesia, khususnya materi ajar menyunting frasa. Metode yang digunakan dalam penelitian ini adalah metode deskriptif kualitatif. Data penelitian ini berupa kata dan frasa. Sumber data penelitian ini ialah kisah narasi mahasiswa Universitas Bina Darma. Pengumpulan data dilakukan dengan teknik baca dan catat. Analisis data menggunakan deskripsi. Hasil penelitian dalam artikel ini sebagai sampel adalah 5 data. Data tersebut dimaksudkan agar dapat direalisasikan dalam pembelajaran Bahasa Indonesia khususnya pada materi menyunting frasa. Realisasi hasil analisis frasa endosentris atributif dalam pembelajaran dapat diaplikasikan dalam materi ajar menyunting frasa. Guru dapat menggunakan hasil analaisis sebagai bahan ajar dalam proses pembelajaran yang disampaikan dalam rencana pembelajaran. 


\section{JURNAL ILMIAH \\ BINA EDUKASI \\ ISSN 1979-8598 E-ISSN: 2655-8378 \\ http://journal.binadarma.ac.id/index.php/jurnalbinaedukasi \\ Vol. 14, No. 1, Juni 2021, 36 - 45}

\section{PENDAHULUAN}

Bahasa memberikan peran yang cukup besar bagi kehidupan sehari-hari, khususnya dalam hal berkomunikasi. Bahasa dan komunikasi juga menjadi hal pokok dalam pembelajaran di sekolah. Dua jenis bahasa, baik bahasa lisan maupun bahasa tulis, menjadi salah satu media dalam belajar. Bahasa lisan dianggap sebagai bahasa primer dengan lambang yang digunakan. Lambang tersebut adalah bunyi yang telah dihasilkan oleh manusia. Bahasa tulis memiliki sifat sekunder. Hal tersebut merupakan rekaman visual, bentuk huruf serta tanda baca (Chaer, 2011). Ilmu Bahasa yang mengkaji tentang frasa yaitu sintaksis. Sintaksis merupakan cabang ilmu linguistik yang membahas mengenai struktur kalimat. Struktur kalimat yang dibahas dalam sintaksis ialah frasa, klausa dan kalimat (Manaf, 2009). Satuan dalam sintaksis disusun atas satuan-satuan yang lebih kecil. Unsur-unsur kecil tersebut salah satunya adalah frasa.

Kridalaksana (2001) menjelaskan bahawa frasa merupakan gabungan dua kata atau lebih yang memiliki sifat tidak predikatif, gabungan tersebut dapat rapat renggang. Frasa Bahasa Indonesia dibedakan menjadi dua, yakni endosentris dan eksosentris. Penelitian ini akan membahas frasa endosentris atributuf. Frase endosentris sendiri, yaitu frasa yang memiliki distribusi yang sama dengan unsurnya. Chaer (2009) juga menambahkan bahwa yang dimaksud dengan frasa endosentris adalah frasa yang hubungannya sangat erat, yang sehingga kedua unsurnya tidak bisa dipisahkan sebagai pengisi fungsi sintaksis. Sejalan dengan Chaer, Emzir, (2012) menyatakan bahwa frasa endosentris merupakan frasa yang mempunyai distribusi yang sama dengan unsurnya, baik semua unsur-unsurnya maupun salah satu unsurnya. Lebih lanjut Ramlan (2005) mengatakan, frasa mempunyai dua sifat yaitu, (1) frasa merupakan satuan gramatik yang terdiri dari dua kata atau lebih, (2) frasa merupakan satuan gramatik yang tidak melebihi batas fungsi unsur klausa, yaitu subjek, predikat, objek, pelengkap, dan keterangan.

Mempelajari ilmu bahasa, kita mengenal yang disebut dengan keterampilan berbahasa. Dalam keterampilan berbahasa ini mengandung empat aspek atau komponen. Komponenkomponen itu meliputi, keterampilan menyimak, keterampilan berbicara, keterampilan membaca, dan keterampilan menulis. Setiap keterampilan bahasa tersebut, memiliki hubungan atau keterkaitan dengan keterampilan berbahasa yang lainnya. Dengan adanya keterkaitan itu, menandakan bahwa dalam mempelajari keterampilan berbahasa tersebut, kita harus memulai dengan cara yang berurutan atau sistematis.

Pada dasarnya, pendidik dapat mengajarkan aspek menulis paragraf atau wacana dengan memerhatikan unsur pembentuknya. Misalnya, kisah naratif dapat menjadi sarana atau media ajar dalam membuat materi dalam mengajarkan frasa, klausa, kalimat maupun wacana. Dengan 


\section{JURNAL ILMIAH \\ BINA EDUKASI \\ ISSN 1979-8598 E-ISSN: 2655-8378 \\ http://journal.binadarma.ac.id/index.php/jurnalbinaedukasi \\ Vol. 14, No. 1, Juni 2021, 36 - 45}

demikian, pemanfaatan bahan ajar berupa wacana narasi dapat memberikan pemahaman tentang aspek unsur pembentuk paragraf itu sendiri, salah satunya frasa.

Salah satu fungsi bahasa sebagai alat komunikasi yaitu penggunaan bahasa tulis dalam sebuah tulisan berbentuk kisah, dalam hal ini khususnya berupa wacana naratif. Wacana naratif merupakan jenis karangan yang mengungkapkan suatu kisah, peristiwa, atau juga pengalaman pribadi dengan berdasarkan urutan-urutan kajadian atau peristiwa. Paragraf naratif ini merupakan paragraf yang berisi mengenai pemaparan suatu kejadian yang dirangkai didalam kesatuan waktu. merupakan salah satu karya sastra yang tersusun dari beberapa kalimat, yang menceritakan mengenai tokoh dan peristiwa secara terstruktur. Berdasarkan Kamus Besar Bahasa Indonesia (KBBI) dalam jaringan menjelaskan bahwa na-ra-tif $a 1$ bersifat narasi; bersifat menguraikan (menjelaskan dsb): karangan yang--; bahasa mereka ini bersifat--; 2 prosa yang subjeknya merupakan suatu rangkaian kejadian.

Penelitian tentang frasa endosentrif atributif sebelumnya pernah dilakukan oleh Hidayah (2019) dengan judul penelitian Frase Nomina Pelaku Endosentris Atributif Bahasa Inggris di Bidang Kantor Depan (Front Office) Hotel. Penelitian itu menghasilkan kategori frasa nomina pelaku endosentris atributif di bidang front office hotel ada dua yakni atributif yang mendahului unsur pusat dan unsur pusat yang mendahului atribut.

Bintari dan Sumarlan (2019) dalam penelitiannya yang berjudul Unsur Pembentuk Frasa Eksosentris dalam Hikayat Hang Tuah ditemukan tiga jenis frasa eksosentris (1) frasa eksosentris direktif dengan unsur pembentuk frasa berupa preposisi+nomina; (2) frasa eksosentris nondirektif dengan unsur pembentuk frasa, yaitu partikel/kata sebutan+adjektiva dan partikel/kata sebutan+nomina; dan (3) frasa eksosentris konektif yang unsur pembentuk frasanya berupa kata penghubung+verba.

Berdasarkan latar belakang di atas, peneliti memiliki ketertarikan untuk mengkaji tulisan mahasiswa semester dua Program Studi Pendidikan Bahasa Indonesia Universitas Bina Darma Palembang. Hal itu karena seluruh mahasiswa itu baru saja melakukan kegiatan menulis yang diterbitkan dalam sebuah buku antologi kisah inspiratif.

\section{METODOLOGI PENELITIAN}

Penelitian ini termasuk dalam penelitian deskripsi kualitatif. Penelitian deskripsi merupakan penelitian dengan didasarkan pada fenomena sosial. Deskripsi memiliki sifat data kualitatif. Menurut Sugiyono (2017), mengatakan bahwa deskriptif adalah sebuah metode penelitian pada dasarnya merupakan cara ilmiah untuk mendapatkan data dengan tujuan dan kegunaan tertentu. Wujud datanya berupa kata, gambar, dan angka yang tidak berbentuk statistik. Teknik pengumpulan data yang digunakan dalam penelitian ini menggunakan teknik baca dan 


\section{JURNAL ILMIAH \\ BINA EDUKASI \\ ISSN 1979-8598 E-ISSN: 2655-8378 \\ http://journal.binadarma.ac.id/index.php/jurnalbinaedukasi \\ Vol. 14, No. 1, Juni 2021, 36 - 45}

catat. Data yang didapat dalam penelitian ini berupa kata, frasa dan kalimat. Sumber data pada penlitian ini didapat dari tulisan naratif mahasiswa program studi Pendidikan Bahasa Indonesia, semester dua di Universitas Bina Darma Palembang.

Langkah dalam pengumpulan data adalah sebagai berikut. Peneliti membedah setiap klausa dan katimat dalam novel, memilah tipe frasa endosentris atributuf kemudian mendeskripsikan bentuk dan makna dari unsur pembentuk frasa. Selanjutnya, penarikan kesimpulan. Teknik analisis data pada penlitian ini menggunakan teknik analisis deskripsi dengan diterangkan permasalahan yang ada kemudian nmenguji keabsahannya.

\section{HASIL DAN PEMBAHASAN}

\subsection{Frasa Endosentris Atributif}

Hasil penelitian disampaikan pada artikel ini adalah frasa endosentris atributif. Ditemukan beberapa frasa endosentris yang terdapat pada tulisan naratif berbentuk kisah oleh mahasiswa semester dua Program Studi Pendidikan Bahasa Indonesia Universitas Bina Darma. Rata-rata merupakan kelas kata nomina pada unsur pusat yang ditemukan. Unsur atributif ditemuan kelas kata nomina dan adjektiva. Berikut kutipan dan analisis data dari frasa endosentris atributif tulisan naratif berbentuk kisah oleh mahasiswa semester dua Program Studi Pendidikan Bahasa Indonesa Universitas Bina Darma.

\section{Cerita ini adalah kisah nyata yang terjadi ketika aku masih duduk di bangku kelas VI SD.}

(Data A-1)

Kutipan kalimat di atas terdapat frasa kisah nyata. Pada frasa kisah nyata terdapat unsur yang berbeda. Kata kisah tergolong kelas kata nomina yang sekaligus menjadi unsur pusat dan kata nyata tergolong dalam adjektiva yang sekaligus menjadi atribut. Dengan adanya perbedaan unsur tersebut maka dapat dipastikan jika frasa kisah nyata merupakan frasa bertipe endosentris atributif.

2. Pahit getir cobaan waktu itu yang aku rasakan ketika kududuk di bangku kelas VI.

(Data A-2)

Kutipan kalimat di atas juga terdapat frasa, yaitu pahit getir cobaan. Pada frasa pahit getir cobaan terdapat unsur yang berbeda. Kata cobaan tergolong kelas kata nomina yang sekaligus menjadi unsur pusat dan kata pahit getir tergolong dalam adjektiva yang menjadi atribut. Dengan adanya perbedaan unsur tersebut maka dapat diartikan jika frasa pahit getir cobaan merupakan frasa bertipe endosentris atributif.

3. Kusempatkan membuat secangkir teh dan kubawakan untuknya. (Data A-3)

Kutipan kalimat di atas juga terdapat frasa, yaitu secangkir teh. Pada frasa secangkir teh yang berfungsi sebagai objek terdapat unsur yang berbeda. Kata teh tergolong kelas kata nomina 


\section{JURNAL ILMIAH \\ BINA EDUKASI \\ ISSN 1979-8598 E-ISSN: 2655-8378 \\ http://journal.binadarma.ac.id/index.php/jurnalbinaedukasi \\ Vol. 14, No. 1, Juni 2021, 36 - 45}

yang sekaligus menjadi unsur pusat dan kata secangkir tergolong dalam numeralia yang menjadi atribut. Dengan adanya perbedaan unsur tersebut maka dapat diartikan jika frasa secangkir teh merupakan frasa bertipe endosentris atributif.

4. waktu kosong kugunakan untuk belajar (Data B-1)

Kutipan kalimat di atas juga terdapat frasa, yaitu waktu kosong. Pada frasa waktu kosong yang berfungsi sebagai subjek terdapat unsur yang berbeda. Kata waktu tergolong kelas kata nomina yang sekaligus menjadi unsur pusat dan kata kosong tergolong dalam adjektiva yang menjadi atribut. Dengan adanya perbedaan unsur tersebut maka dapat diartikan jika frasa waktu kosong merupakan frasa bertipe endosentris atributif.

5. Aku sudah mempersiapkan diri untuk mengikuti tes perguruan tinggi kedinasan. (Data B-2)

Kutipan kalimat di atas terdapat frasa, yaitu Perguruan tinggi kedinasa. Pada frasa tes perguruan tinggi kedinasan yang berfungsi sebagai keterangan terdapat unsur yang berbeda. Kata tes tergolong kelas kata nomina yang sekaligus menjadi unsur pusat dan kata perguruang tinggi kedinasan tergolong dalam nomina yang menjadi atribut. Dengan adanya perbedaan unsur tersebut maka dapat diartikan jika frasa waktu kosong merupakan frasa bertipe endosentris atributif.

6. Kaki kecilku tidak cukup cepat melangkah mengejar pikiranku yang sudah kemana-mana.

(Data C-1)

Kutipan kalimat di atas terdapat frasa, yaitu Kaki kecil. Pada frasa kaki kecil yang berfungsi sebagai subjek terdapat unsur yang berbeda. Kata kaki tergolong kelas kata nomina yang sekaligus menjadi unsur pusat dan kata kecil tergolong dalam adjektiva yang menjadi atribut. Dengan adanya perbedaan unsur tersebut maka dapat diartikan jika frasa kaki kecil merupakan frasa bertipe endosentris atributif.

7. Bapak melajukan mobilnya dengan sangat cepat. (Data C-2)

Kutipan kalimat di atas terdapat frasa, yaitu sangat cepat. Pada frasa sangat cepat yang berfungsi sebagai keterangan terdapat unsur yang berbeda. Kata cepat tergolong kelas kata adjektiva yang sekaligus menjadi unsur pusat dan kata sangat tergolong dalam advarbia yang menjadi atribut. Dengan adanya perbedaan unsur tersebut maka dapat diartikan jika frasa sangat cepat merupakan frasa bertipe endosentris atributif.

8. Langit mendung dengan awan gelap, dilanjutkan hujan deras, dan angin kencang, namun kami tetap melanjutkan perjalanan. (Data C-3)

Kutipan kalimat di atas terdapat lima frasa, yaitu langit mendung, awan gelap, hujan deras, angin kencang, dan tetap melanjutkan.

Pertama, pada frasa langit mendung terdapat unsur yang berbeda. Kata langit tergolong kelas kata nomina yang sekaligus menjadi unsur pusat dan kata mendung tergolong dalam 


\section{JURNAL ILMIAH \\ BINA EDUKASI \\ ISSN 1979-8598 E-ISSN: 2655-8378 \\ http://journal.binadarma.ac.id/index.php/jurnalbinaedukasi \\ Vol. 14, No. 1, Juni 2021, 36 - 45}

adjektiva yang menjadi atribut. Dengan adanya perbedaan unsur tersebut maka dapat diartikan jika frasa langit mendung merupakan frasa bertipe endosentris atributif.

Kedua, Pada frasa awan gelap terdapat unsur yang berbeda. Kata awan tergolong kelas kata nomina yang sekaligus menjadi unsur pusat dan kata gelap tergolong dalam adjektiva yang menjadi atribut. Dengan adanya perbedaan unsur tersebut maka dapat diartikan jika frasa awan gelap merupakan frasa bertipe endosentris atributif.

Ketiga, pada frasa hujan deras terdapat unsur yang berbeda. Kata hujan tergolong kelas kata nomina yang sekaligus menjadi unsur pusat dan kata deras tergolong dalam adjektiva yang menjadi atribut. Dengan adanya perbedaan unsur tersebut maka dapat diartikan jika frasa hujan deras merupakan frasa bertipe endosentris atributif.

Keempat, pada frasa angina kencang terdapat unsur yang berbeda. Kata angin tergolong kelas kata nomina yang sekaligus menjadi unsur pusat dan kata kencang tergolong dalam adjektiva yang menjadi atribut. Dengan adanya perbedaan unsur tersebut maka dapat diartikan jika frasa angina kencang merupakan frasa bertipe endosentris atributif.

Kelima, pada frasa tetap melanjutkan yang berkedudukan sebagai predikat terdapat unsur yang berbeda. Kata melanjutkan tergolong kelas kata verba yang sekaligus menjadi unsur pusat dan kata tetap tergolong dalam verba yang menjadi atribut. Dengan adanya perbedaan unsur tersebut maka dapat diartikan jika frasa tetap merupakan frasa bertipe endosentris atributif.

9. Gejala nervous mulai muncul seperti keringat dingin, susah bicara, dan pandangan gak fokus. (Data D-1)

Kutipan kalimat di atas juga terdapat empat frasa yang menduduki fungsi subjek dan keterangan. Frasa-frasa itu, meliputi, gejala nervous, keringat dingin, susah bicara, dan pandangan gak fokus. Pada frasa gejala nervous yang berfungsi sebagai subjek terdapat unsur yang berbeda. Kata gejala tergolong kelas kata nomina yang sekaligus menjadi unsur atribut dan kata nervous yang dalam bahasa Indonesia diartikan gugup atau grogi tergolong dalam adjektiva yang menjadi unsur pusat. Dengan adanya perbedaan unsur tersebut maka dapat diartikan jika frasa gejala nervous merupakan frasa bertipe endosentris atributif.

Kedua, pada frasa keringat dingin yang berkedudukan sebagai keterangan terdapat unsur yang berbeda. Kata keringat tergolong kelas kata nomina yang sekaligus menjadi unsur pusat dan kata dingin tergolong dalam adjektiva yang menjadi atribut. Dengan adanya perbedaan unsur tersebut maka dapat diartikan jika frasa keringat dingin merupakan frasa bertipe endosentris atributif.

Ketiga, pada frasa susah bicara yang berkedudukan sebagai keterangan terdapat unsur yang berbeda. Kata bicara tergolong kelas kata verba yang sekaligus menjadi unsur pusat dan kata susah tergolong dalam adjektiva yang menjadi atribut. Dengan adanya perbedaan unsur 


\section{JURNAL ILMIAH \\ BINA EDUKASI \\ ISSN 1979-8598 E-ISSN: 2655-8378 \\ http://journal.binadarma.ac.id/index.php/jurnalbinaedukasi \\ Vol. 14, No. 1, Juni 2021, $36-45$}

tersebut maka dapat diartikan jika frasa susah bicara merupakan frasa bertipe endosentris atributif.

Kedua, pada frasa pandangan gak fokus yang berkedudukan sebagai keterangan terdapat unsur yang berbeda. Kata pandangan tergolong kelas kata nomina yang sekaligus menjadi unsur pusat dan kata gak dan focus tergolong dalam verba yang menjadi atribut. Dengan adanya perbedaan unsur tersebut maka dapat diartikan jika frasa pandangan gak focus merupakan frasa bertipe endosentris atributif.

10. Pikiranku melarang keras untuk bertindak demikian. (Data D-2)

Kutipan kalimat di atas terdapat frasa, yaitu melarang keras. Pada frasa melarang keras yang berfungsi sebagai predikat terdapat unsur yang berbeda. Kata melarang tergolong kelas kata verba yang sekaligus menjadi unsur pusat dan kata keras tergolong dalam adjektiva yang menjadi atribut. Dengan adanya perbedaan unsur tersebut maka dapat diartikan jika frasa melarang keras merupakan frasa bertipe endosentris atributif.

\subsection{Realisasi Frasa Atributif Materi Ajar Menyunting Frasa Siswa Kelas X SMA}

Realisasi hasil analisis frasa endosentris atributif yang telah dilakukan dapat diaplikasikan dalam pembelajaran Bahasa Indonesia pada materi ajar menyunting frasa. Guru bisa menggunakan hasil analaisis ini sebagai bahan ajar yang disampaikan di dalam rencana pembelajaran. Tulisan ini menyajikan beberapa data terkait frasa endosentris atributif yang digunakan dalam realisasi dalam pembelajaran. Reaslisasi tersebut dapat disampaikan melalui contoh yang digunakan dalam materi ajar. Hal tersebut diharapkan bisa membantu guru dalam menerangkan jenis dan contoh frase endosentris atributuif kepada peserta didik.

Terdapat unsur pusat dan atribut pada frasa atributif. Unsur pusat memiliki kedudukan sebagai unsur yang diterangkan. Sedangkan unsur atribut memiliki kedudukan sebagai unsur yang diterangkan. Unsur pusat diterangkan unsur atributif. Peserta didik diharuskan mampu membedakan kedua hal tersebut. Dalam kondisi saat ini, dilakukan pembelajaran daring. Sehingga peserta didik diharapkan bisa memberikan contoh yang bisa dengan baik diterima oleh peseerta didik.

Realisasi yang dirancang, yaitu dengan memasukkan contoh-contoh dalam rencana pembelajaran yang disusun pendidik. Pendidik memberikan materi kepada peserta didik sesuai dengan kompetensi dasar yakni meyunting frasa. Dalam proses menyunting, peserta didik diharuskan dapat memahami bagaimana proses pembentukan frasa endosentris atributif. Berikut ini adalah rencana pembelajaran realisasi hasil penelitian frasa endosentris atributif pada tulisan mahasiswa Program Studi Pendidikan Bahasa Indonesia Semester dua, Universitas Bina Darma palembang. 


\section{JURNAL ILMIAH}

BINA EDUKASI

ISSN 1979-8598 E-ISSN: 2655-8378

http://journal.binadarma.ac.id/index.php/jurnalbinaedukasi

Vol. 14, No. 1, Juni 2021, 36 - 45

Tabel 1. Rencana Pelaksanaan Pembelajaran

$$
\text { Pendahuluan }
$$

a. Guru memberi salam kepada peserta didik kemudian peserta didik menjawabnya sebelum pembelajaran melalui video conference Zoom meeting dimulai.

b. Guru mengecek presensi peserta didik melalui google form.

c. Peserta didik yang paling awal masuk ruang webmeet memimpin berdo'a sebelum memulai pembelajaran bersama-sama

d. Peserta didik melakukan apersepsi bersama guru mengenai pembelajaran yang sudah dilaksanakan pada pertemuan sebelumnya. Hal itu sebagai bekal awal pembelajaran yang akan dilakukan.

e. Peserta didik melakukan tanya jawab dengan guru berkaitan dengan materi selanjutnya

f. Peserta didik menyimak paparan materi pendahuluan.

\section{Kegiatan Inti (30 menit)}

a. Guru meminta peserta didik untuk membaca contoh wacana yang terdapat frasa endosenstris.

b. Peserta didik mencermati penjelasan guru mengenai frase endosentris.

c. Peserta didik bersama dengan guru melakukan tanya jawab mengenai materi yang telah disampaikan oleh guru.

d. Guru memberikan penjelasan mengenai frasa endosentris.

e. Peserta didik diminta membuat kelompok agar menganalisis frase endosentris secara berkelompok yang kemudian didiskusikan antar anggota kelompok

f. Guru memantau keaktifan peserta didik menganalisis frase endosentris

g. Setiap kelompok mempresentasikan hasil karya masing-masing, sedangkan kelompok lain diminta untuk menanggapi dan memberikan penilaian tentang hasil karya kelompok lain.

\section{Penutup}

a. Guru beserta peserta didik melakukan refleksi bersama untuk memberi evaluasi atas rangkaian pembelajaran yang telah dilakukan. Hasil evaluasi yang diperoleh dapat dimanfaatkan oleh peserta didik dan guru pada pembelajaran selanjutnya.

b. Guru memberikan umpan balik terhadap proses dan hasil pembelajaran.

c. Guru melakukan kegiatan tindak lanjut dalam bentuk pemberian tugas, baik tugas individual maupun kelompok.

d. Guru menginformasikan rencana kegiatan pembelajaran untuk pertemuan Berikutnya 


\section{JURNAL ILMIAH}

BINA EDUKASI

ISSN 1979-8598 E-ISSN: 2655-8378

http://journal.binadarma.ac.id/index.php/jurnalbinaedukasi

Vol. 14, No. 1, Juni 2021, $36-45$

\section{SIMPULAN}

Berdasarkan pembahasan frasa endosentris atributif dalam kisah naratif oleh mahasiswa Program Studi Pendidikan Bahasa Indonesia Semester dua Universitas Bina Darma Palembang, dapat disimpulkan bahwa dalam tulisan itu banyak menggunakan frasa endosentris khususnya endosentris atributif. Kandungan informasi yang tidak berubah menjadikan frasa dapat dikategorikan sebagai frasa endosentris atributif. Terdapat dua unsur dalam frasa atributif, yaitu unsur pusat dan unsur atribut sebagai penjelas dari unsur pusat. Dalam temuan, unsur pusat yang paling banyak muncul berkategori nomina. Sedangkan unsur penjelas paling banyak berkategori nomina dan adjektiva. Frasa yang muncul memiliki fungsi kalimat sebagai subjek, predikat, objek, dan keterangan.

Realisasi hasil analisis frasa endosentris atributif dalam pembelajaran dapat diaplikasikan dalam materi ajar menyunting frasa sesuai dengan silabus Bahasa Indonesia kelas X SMA. Guru dapat menggunakan hasil analisis ini sebagai bahan ajar dalam proses pembelajaran yang disampaikan dalam rencana pembelajaran. Reaslisasi hasil analisis tersebut dapat disampaikan melalui contoh-contoh yang digunakan dalam materi ajar. 


\section{DAFTAR PUSTAKA}

Bintari, Kartika dan Sumarlan. (2019). Unsur Pembentuk Frasa Eksosentris dalam Hikayat Hang Tuah. Retorika. Vol 12 No. 2. http://ojs.unm.ac.id/retorika.

Chaer, Abdul. (2009). Pengantar Sintaksis Bahasa Indonesia. Jakarta: PT Rineka Cipta

Chaer, Abdul. (2011). Tata Bahasa Praktis Bahasa Indonesia. Jakarta: Rineka Cipta.

Emzir. 2012. Metodelogi Penelitian Pendidikan Kuantitatif dan Kualitatif. Jakarta: PT RajaGrafindo Persada

Hidayah, Arini. (2019). Frase Nomina Pelaku Endosentris Atributif Bahasa Inggris di Bidang Kantor Depan (Front Office) Hotel. Haluan Sastra Budaya. Vol 3, No 2. https://jurnal.uns.ac.id/hsb/article/view/31862/26915.

Kamus Besar Bahasa Indonesia (Daring). Arti Kata Naratif. https://www.kbbi.co.id/artikata/naratif._Diunduh tanggal 14 April 2021.

Kridalaksana, Harimurti. (2001). Kamus Linguistik. Jakarta: Gramedia.

Manaf, Ngusman Abdul. (2009). Sintaksis: Teori dan Terapannya dalam Bahasa Indonesia. Padang: Sukabina Press.

Ramlan. M. (2005). Ilmu Bahasa Indonesia Sintaksis. Yogyakarta: CV. Karyono.

Silabus K13 Bahasa Indonesia kelas $X$. (Daring). https://www.academia.edu/6551626/1_silabus_bahasa_indonesia_kelas_x_wajib. Diunduh tanggal 1 Juni 2021.

Sugiyono. (2017). Metode Penelitian Kuantitatif, Kualitatif, dan R\&D. Bandung : Alfabeta, CV. 